\title{
Panduan Praktis Instalasi Program Aplikasi INLISLite Versi 3
}

Oleh Didik Pribadi, S.Kom

\section{Persiapan}

Program aplikasi INLISLite Versi 3 dirancang agar dapat digunakan oleh semua perpustakaan baik itu yang mempunyai tenaga ahli di bidang Teknologi Informasi (TI) maupun yang tidak. Oleh karena itu tersedia dua jenis paket instalasi untuk aplikasi ini, yaitu Paket Instalasi Portable yang dapat berjalan pada sistem operasi Windows dan Paket Instalasi Source Code yang dapat digunakan pada sistem operasi apa saja yang memenuhi kebutuhan minimal program aplikasi ini. Dalam panduan ini akan dijelaskan cara Instalasi Portable pada sistem operasi Windows dan Instalasi Permanen yang menggunakan paket Instalasi Source Code pada sistem operasi ubuntu desktop. Pada Instalasi Portable semua aplikasi pendukung sudah termasuk dalam file installer dan pengaturan aplikasi pendukung telah disesuaikan. Instalasi permanen ditujukan untuk perpustakaan yang mempunyai tenaga ahli di bidang TI karena hanya disediakan source code dan file database kosong sedangkan pemasangan aplikasi pendukung dan pengaturan aplikasi pendukung harus disesuaikan sendiri.

Kebutuhan minimal sistem komputer untuk instalasi program aplikasi perpustakaan INLISLite Versi 3 adalah:

- Prosesor $1 \mathrm{GHz}$

- RAM 1 GB

- Kapasitas harddisk disediakan untuk folder sourcecode (termasuk folder konten digital awal) sebesar 1024MB (1 GB)

- Apache Webserver 2.4

- PHP 5.6

- MySQL Server 5.5 / MariaDB 10 atau lebih baru

- Program aplikasi Chrome/Mozilla/Opera versi terbaru yang dilengkapi dengan plugin flashplayer

- Program aplikasi pembaca dokumen PDF seperti AcrobatReader, NitroPDFReader, dan sejenisnya

- Program aplikasi Ms. Word dan Excell atau OpenOffice Writer dan Calc 


\section{Instalasi Portable.}

Sebelum melakukan instalasi portable, unduh paket instalasi portabel terbaru pada http://inlislite.perpusnas.go.id/?read=installerphp. Dalam paket ini aplikasi INLISLite versi 3 dikemas dalam bentuk paket web server terpadu XAMPP portabel yang siap dijalankan

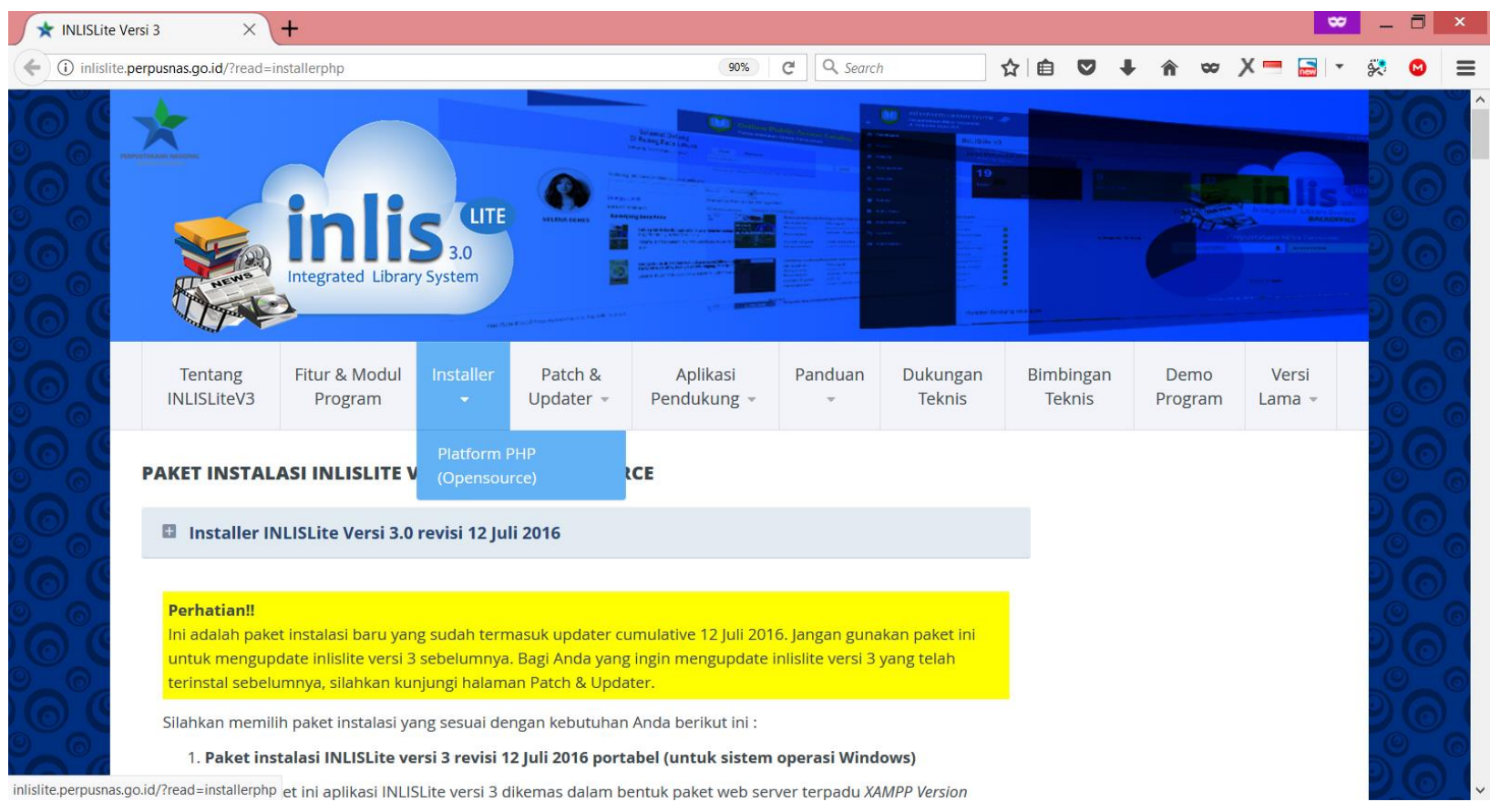

Gambar 1. Halaman unduh installer INLISLite V3

Langkah-langkah instalasi paket ini :

A. Bukalah paket instalasi dalam bentuk rar ini dengan program aplikasi kompresi WINRAR versi 5.21 atau lebih baru

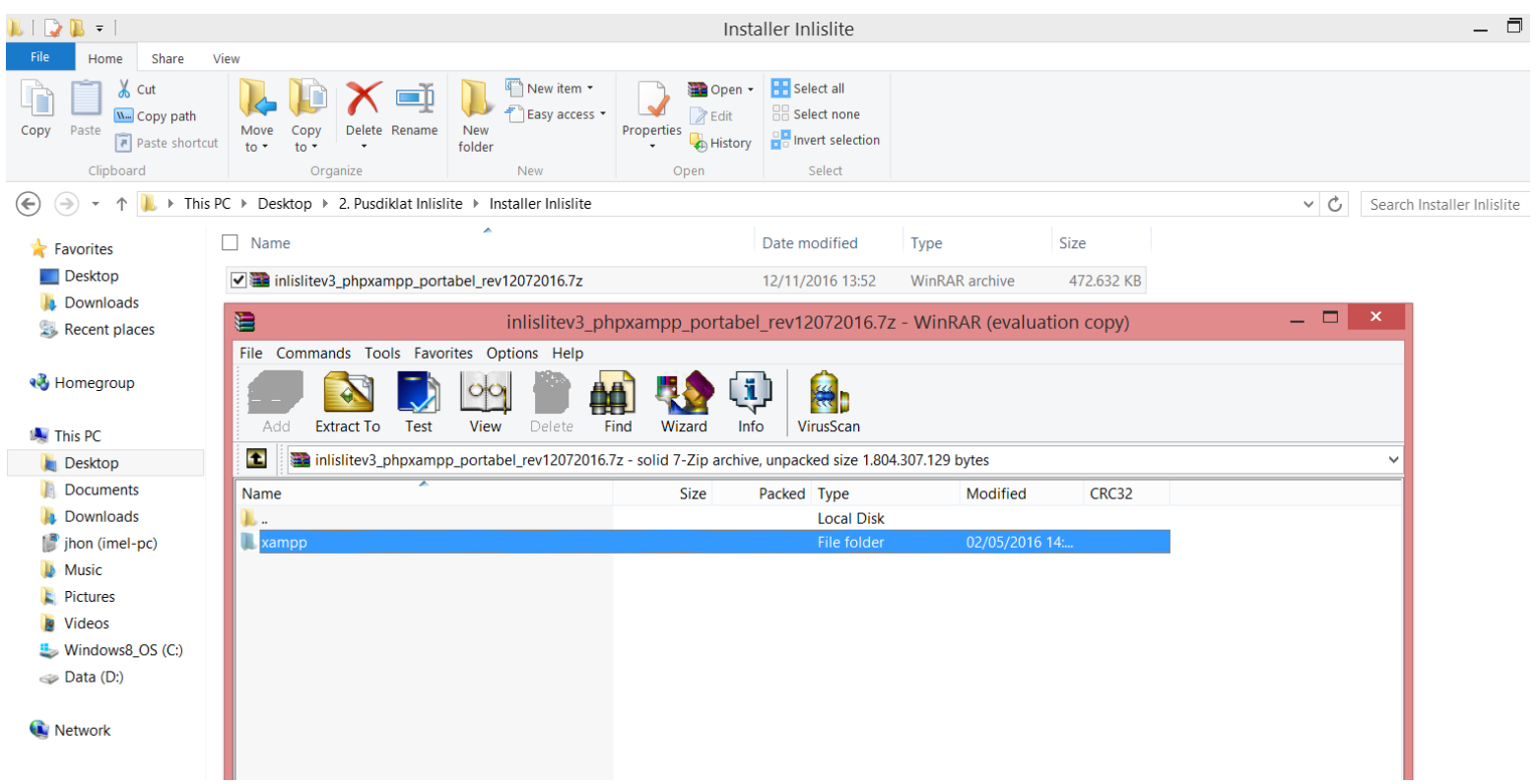

Gambar 2. Buka file paket instalasi INLISLite v3 Portabel 


\section{B. Extract folder xampp ke dalam root drive C. Hasil ekstraksi akan terlihat sebagai c: :xampp}

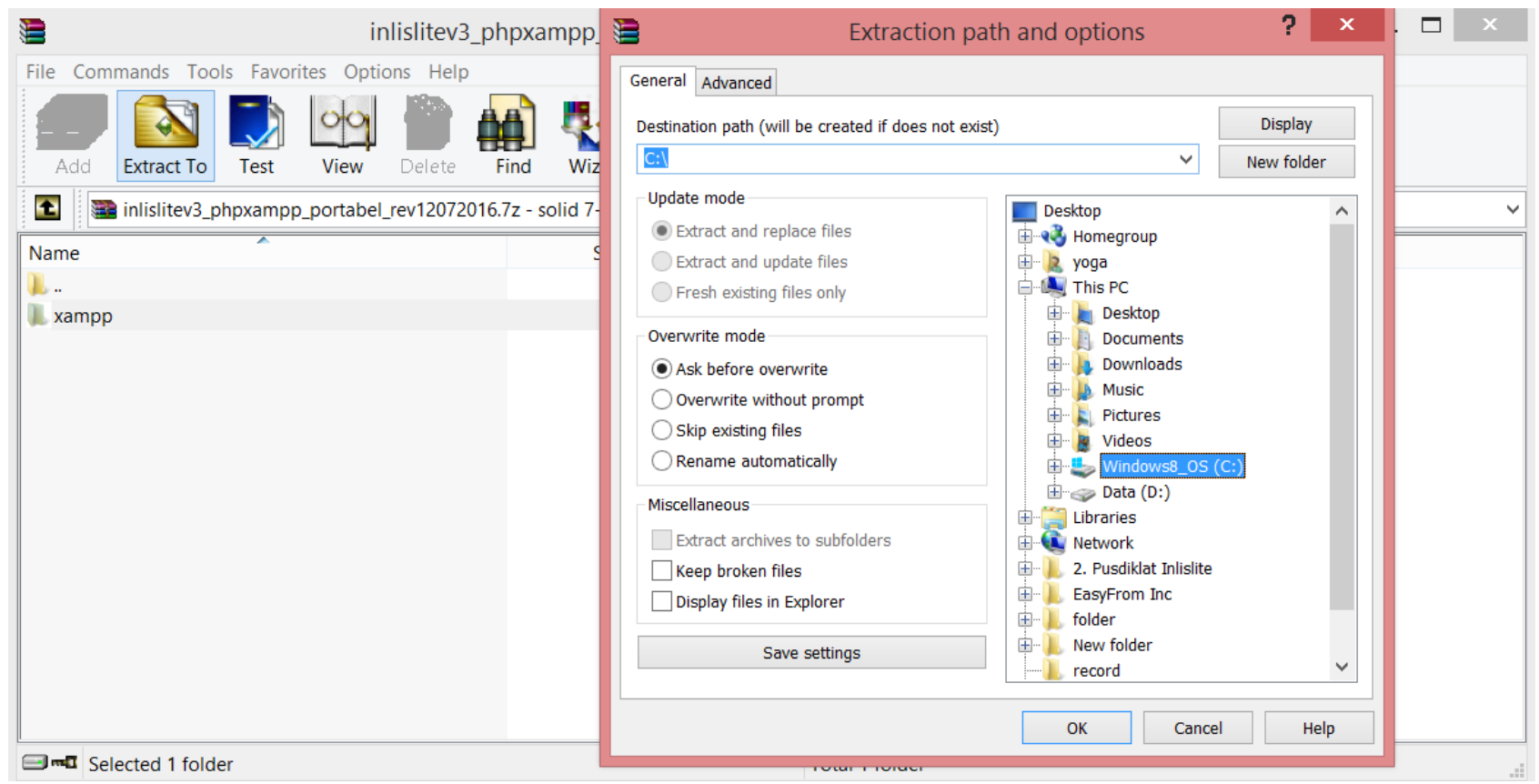

Gambar 3. Extract paket instalasi pada drive C

\section{Bukalah folder xampp}

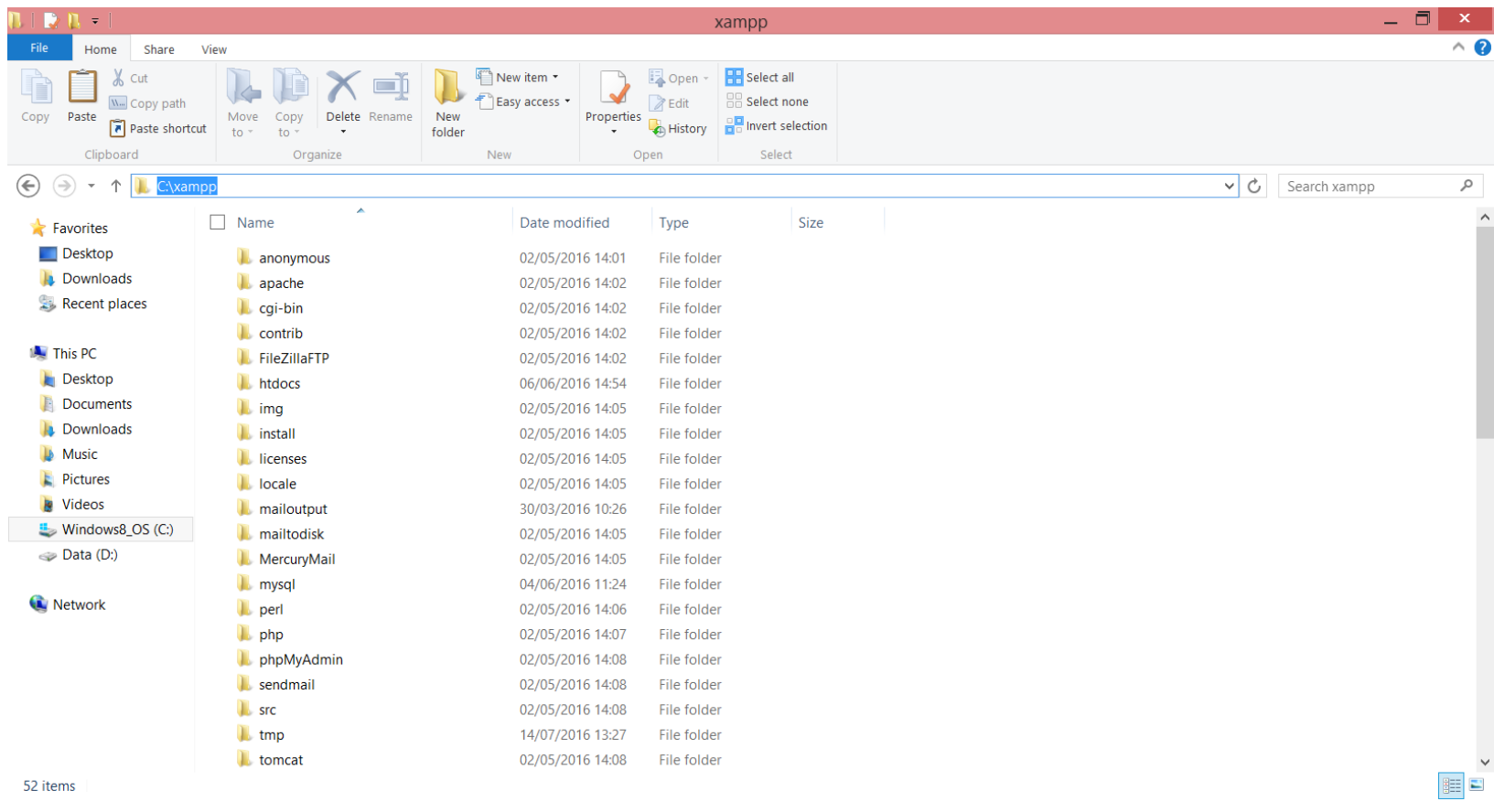

Gambar 4. Folder xampp 
D. Klik ganda file xampp-control.exe atau klik kanan pada file xampp-control.exe lalu klik Open

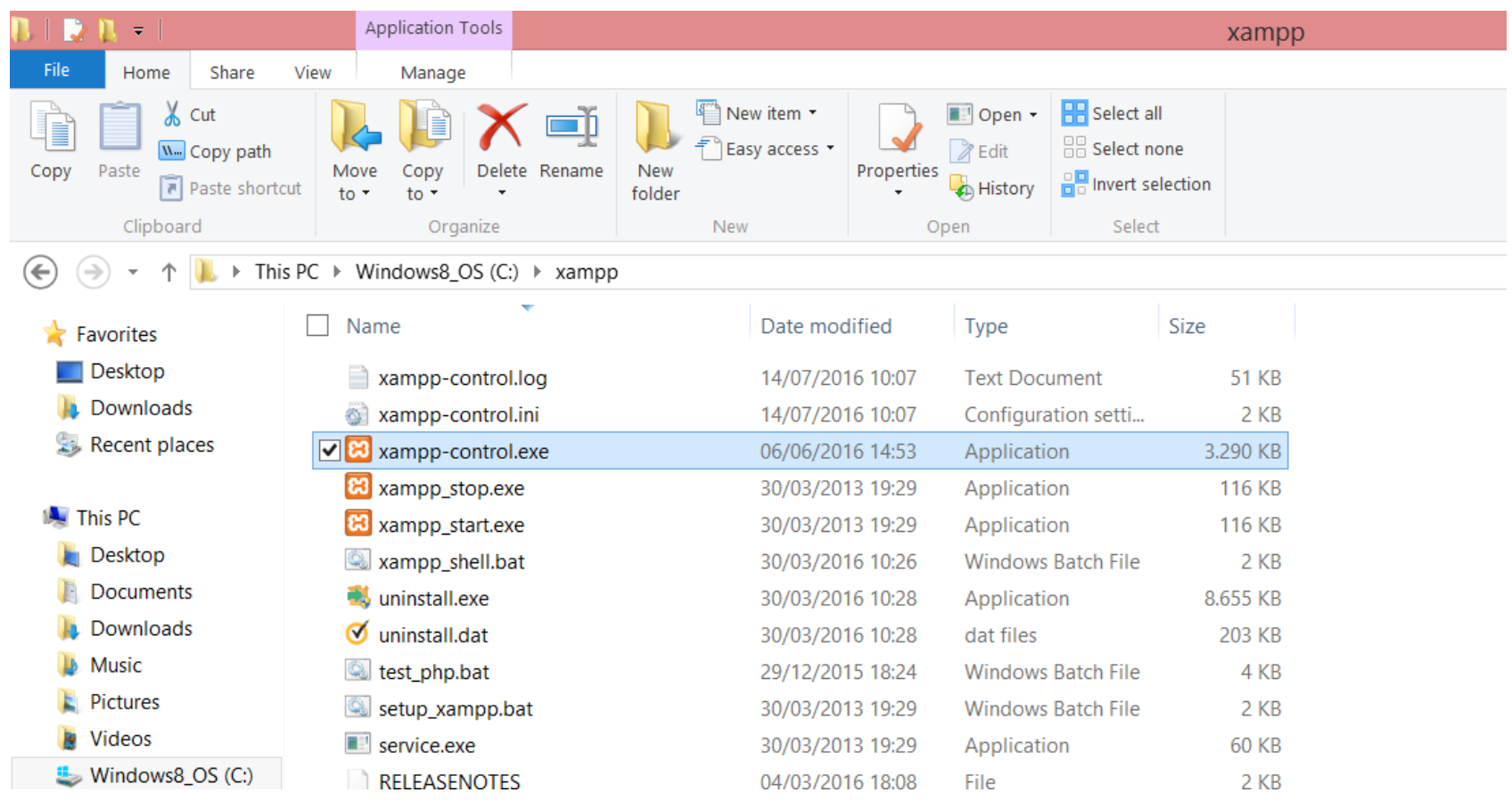

Gambar 5. Jalankan xampp-control.exe

E. Klik tombol Start pada Module Apache dan Module MySQL

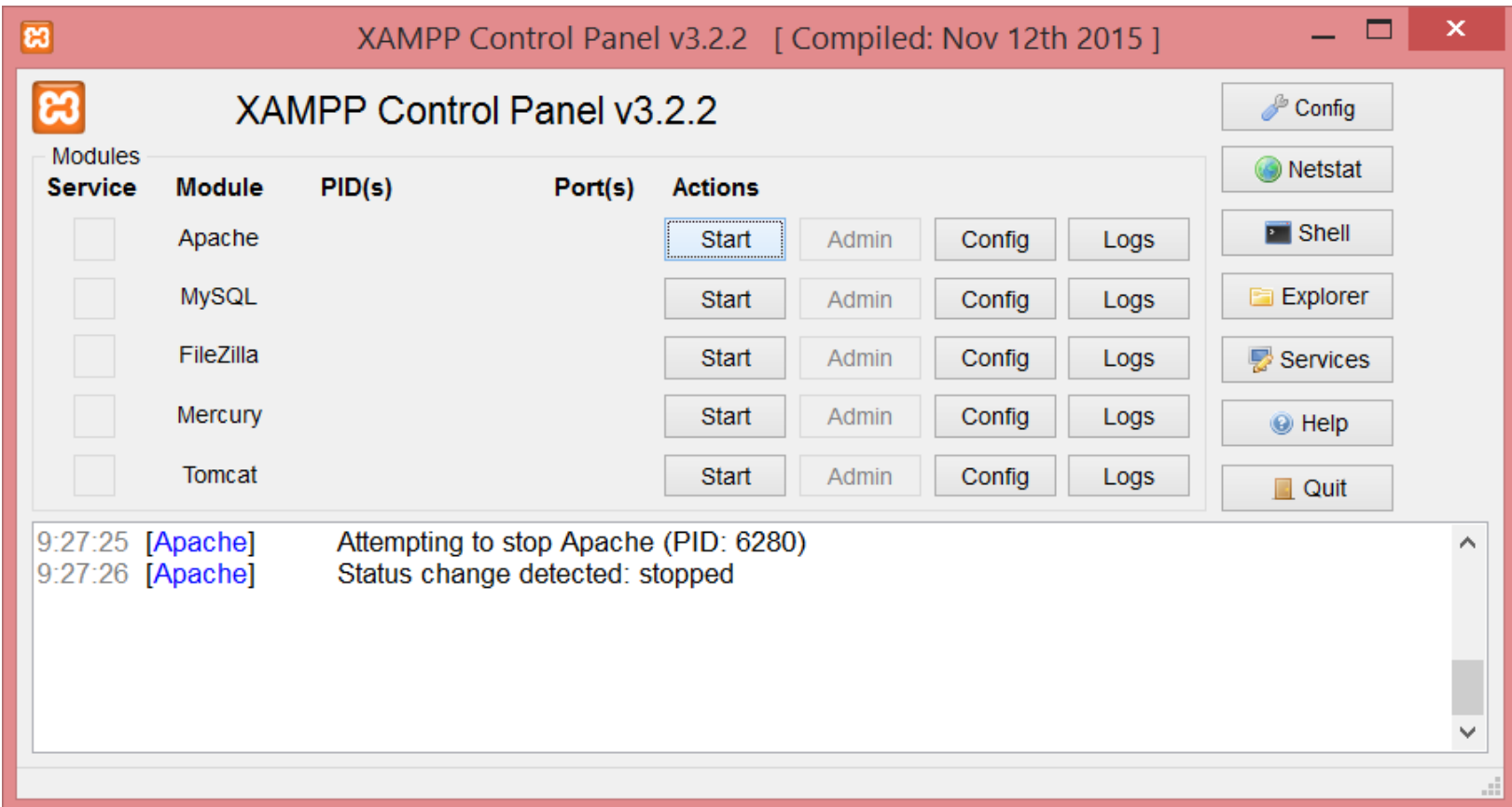

Gambar 6. Jalankan module Apache dan MySql 


\begin{tabular}{|c|c|c|c|c|c|c|c|c|c|}
\hline $\mathscr{\infty}$ & \multicolumn{7}{|c|}{ XAMPP Control Panel v3.2.2 [ Compiled: Nov 12th 2015 ] } & $-\square$ & $\mathbf{x}$ \\
\hline$\ddot{\theta}$ & \multicolumn{7}{|c|}{ XAMPP Control Panel v3.2.2 } & Sonfig & \\
\hline \multirow[t]{6}{*}{$\begin{array}{l}\text { Modules } \\
\text { Service }\end{array}$} & Module & PID(s) & Port(s) & Actions & & & & (1) Netstat & \\
\hline & Apache & $\begin{array}{l}6636 \\
4420\end{array}$ & 444,8123 & Stop & Admin & Config & Logs & Shell & \\
\hline & MySQL & 2964 & 3309 & Stop & Admin & Config & Logs & Explorer & \\
\hline & Filezilla & & & Start & Admin & Config & Logs & Services & \\
\hline & Mercury & & & Start & Admin & Config & Logs & (9) Help & \\
\hline & Tomcat & & & Start & Admin & Config & Logs & — Quit & \\
\hline \multirow{2}{*}{\multicolumn{2}{|c|}{$\begin{array}{l}\text { 9:27:25 [Apache] } \\
\text { 9:27:26 [Apache] } \\
\text { 9:35:27 [Apache] } \\
\text { 9:35:27 [Apache] } \\
\text { 9:35:29 [mysql] } \\
\text { 9:35:29 [mysql] }\end{array}$}} & $\begin{array}{l}\text { Attem } \\
\text { Statu } \\
\text { Attem } \\
\text { Statu } \\
\text { Attem } \\
\text { Status }\end{array}$ & $\begin{array}{l}\text { top Apach } \\
\text { detected: } \\
\text { tart Apach } \\
\text { detected: } \\
\text { tart MySQL } \\
\text { detected: r }\end{array}$ & $\begin{array}{l}\text { (PID: } 62 \\
\text { opped } \\
\text { app... } \\
\text { Inning } \\
\text { app... } \\
\text { Inning }\end{array}$ & & & & & $\wedge$ \\
\hline & & & & & & & & & $\checkmark$ \\
\hline
\end{tabular}

Gambar 7. Module Apache dan Mysql sudah berjalan

F. Jalankan aplikasi browser Chrome/Mozilla/Opera versi terbaru dan pada kotak alamat URL browser ketikkan http://localhost:8123/inlislite3 lalu tekan tombol enter pada keyboard

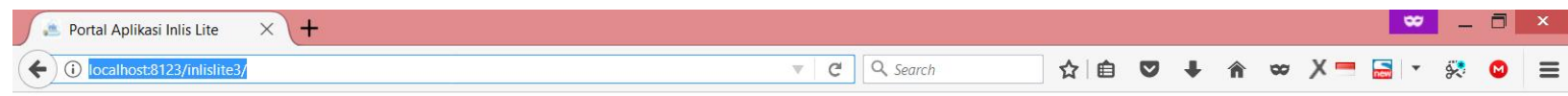

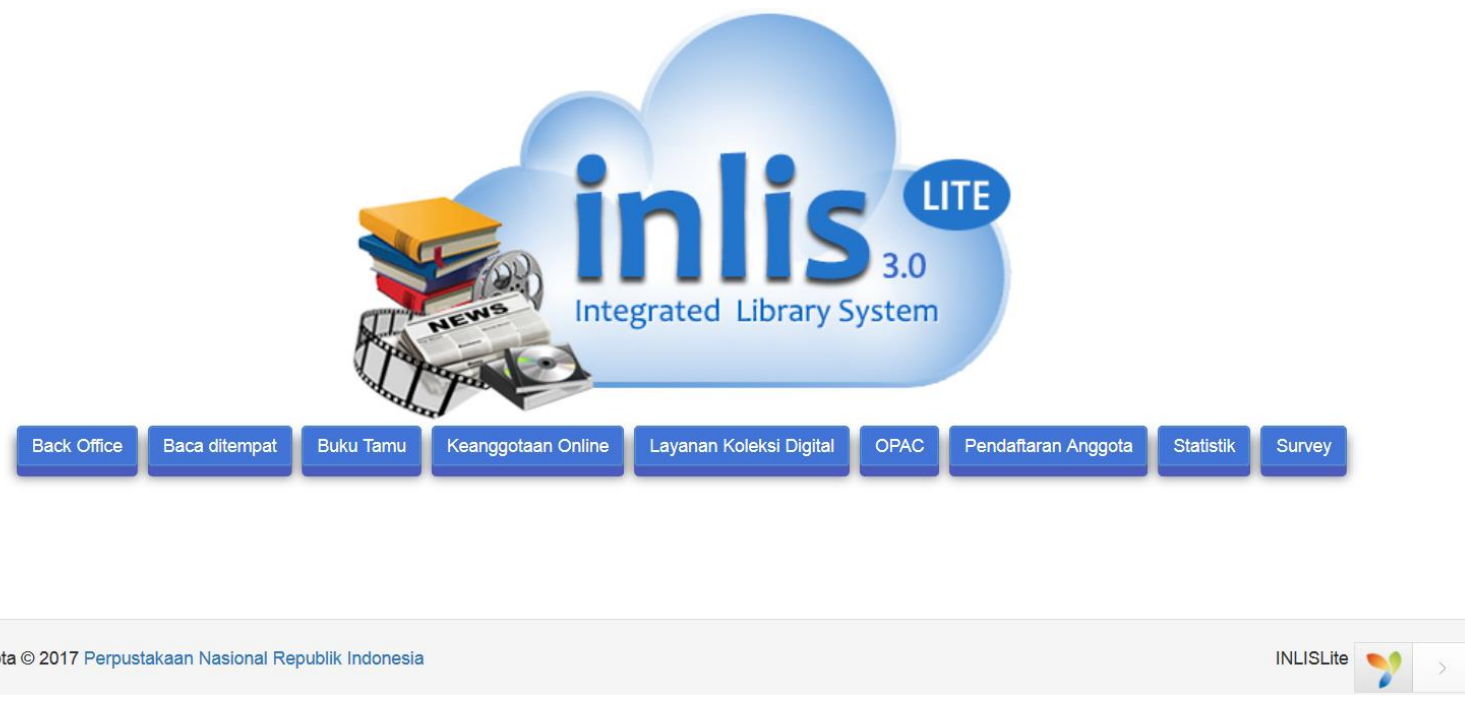

Gambar 8. INLISLite Versi 3.0 berjalan pada browser 


\section{Instalasi Permanen}

Sebelum melakukan instalasi permanen, unduh Paket source code INLISLite Versi 3 terbaru dan file database kosong INLISLite di http://inlislite.perpusnas.go.id/?read=installerphp. Dalam paket source code aplikasi INLISLite versi 3 tidak dikemas dengan server terpadu jadi diperlukan web server, compiler PHP dan database yang memenuhi syarat minimum untuk menjalankan INLISLite, dalam hal ini aplikasi-aplikasi tersebut bisa didapat dengan menggunakan web server terpadu xampp yang dapat diunduh di https://www.apachefriends.org/download.html. Pada panduan ini instalasi akan diterapkan pada sistem operasi Ubuntu Desktop.

Langkah-langkah instalasi paket ini :

A. Download xampp yang sesuai dengan kebutuhan INLISLite Versi 3

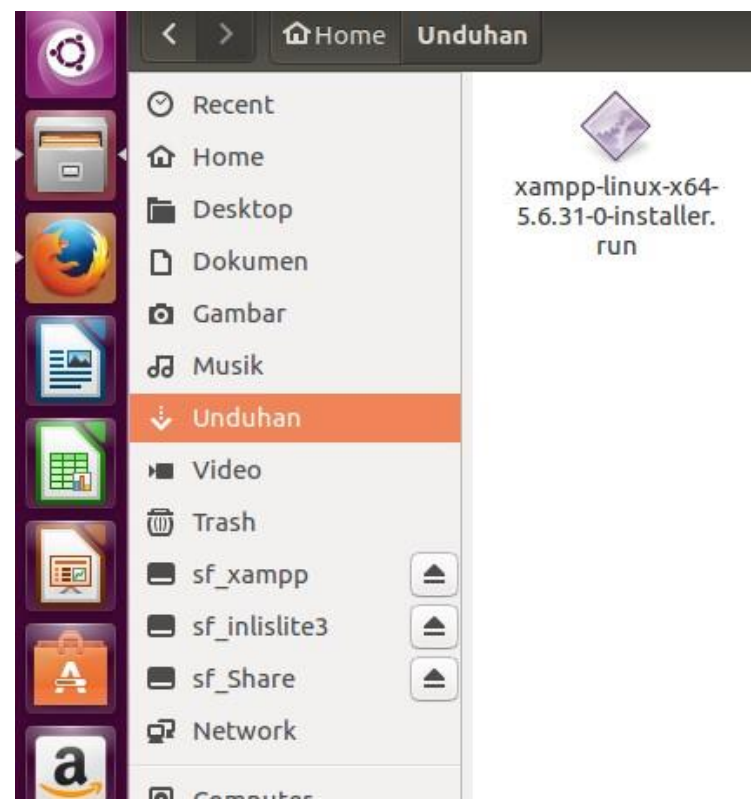

Gambar 9. Installer xampp yang sudah diunduh

B. Buka aplikasi Terminal lalu tambahkan izin agar xampp dapat dijalankan dengan mengetikkan 'sudo chmod $+x$ xampp-linux-64-5.6.31-0-installer.run' dan jalankan installer xampp dengan mengetikkan './xampp-linux-64-5.6.31-0-installer.run' 


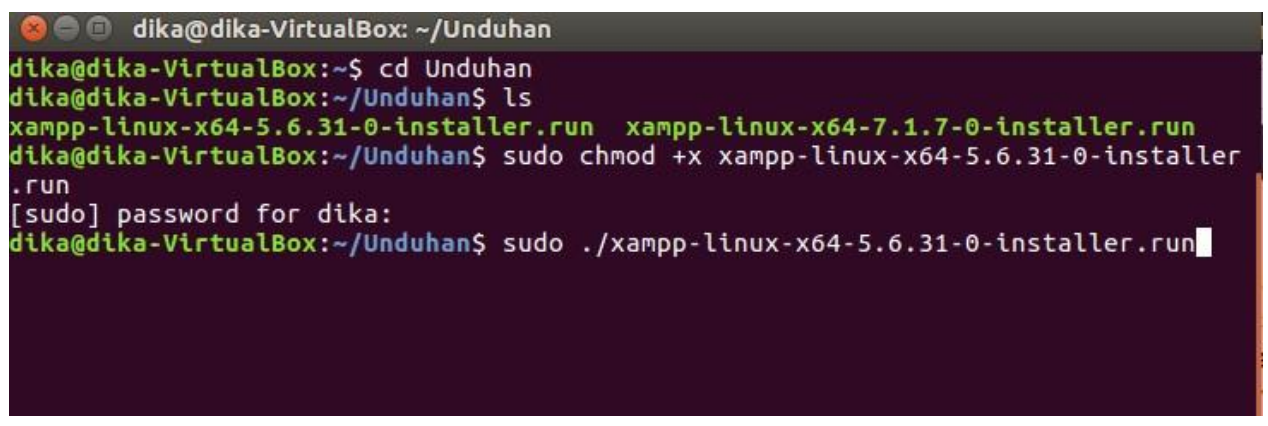

Gambar 10. Menjalankan installer xampp melalui terminal

C. Ikuti prosedur instalasi dan jika sudah berhasil menginstall xampp akan muncul tampilan seperti pada gambar 11

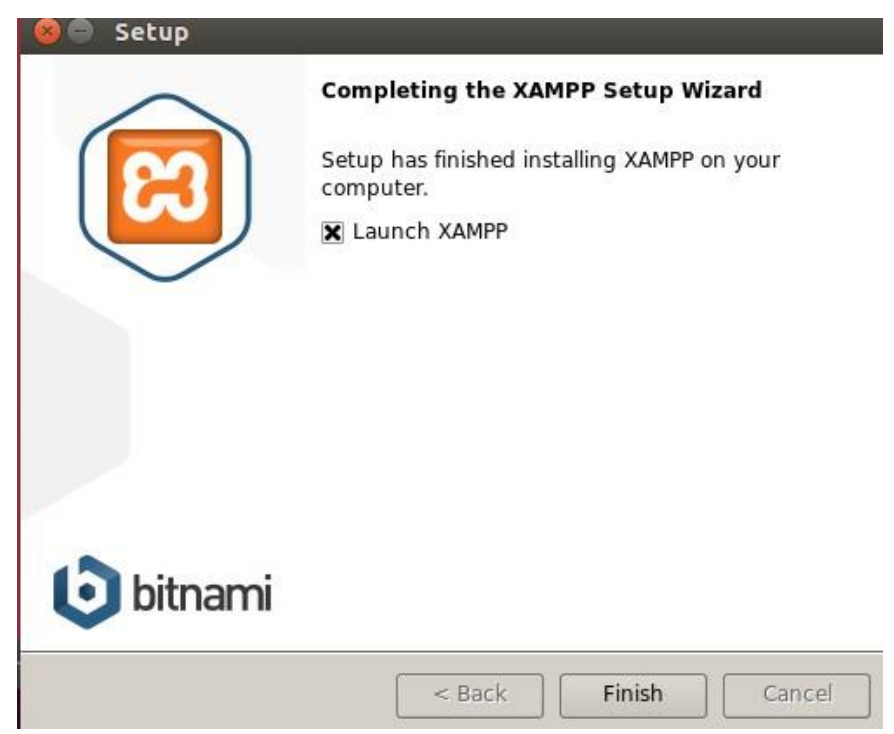

Gambar 11. Instalasi xampp selesai

D. Untuk menjalankan XAMPP secara manual (melalui terminal) ketikkan 'sudo lopt/lampp/lampp start'

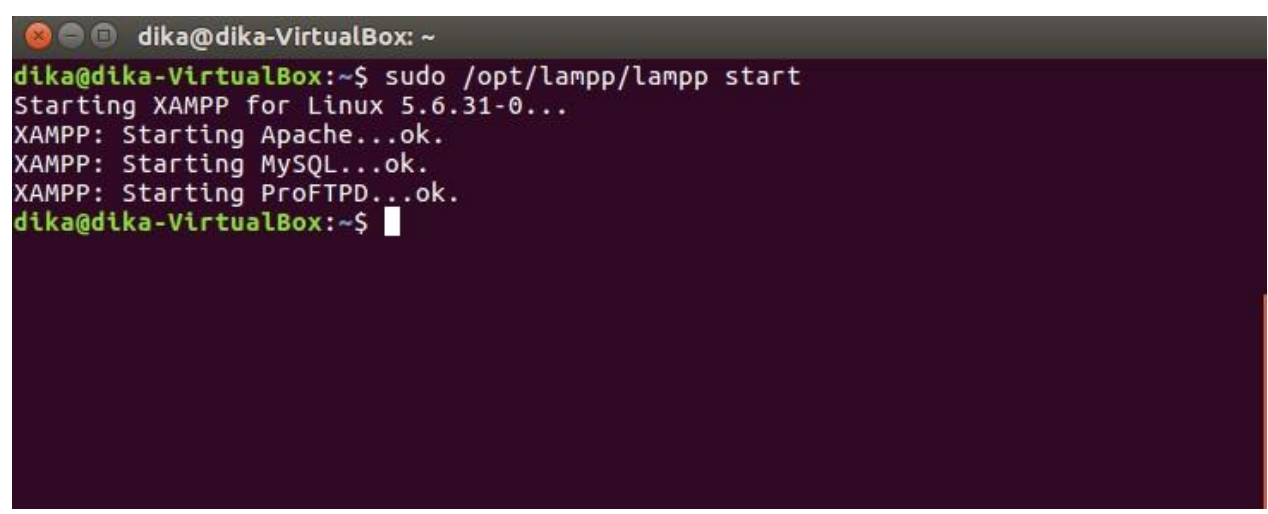

Gambar 12. Menjalankan XAMPP secara manual

E. Extract paket source code Inlislite Versi 3 yang sudah diunduh dan pindahkan kedalam folder /opt/lampp/ 
F. Lakukan pengaturan folder htdocs dengan mengetikkan 'sudo chmod $-R 777$ htdocs' pada Terminal agar INLISLite Versi 3 dapat menambah file dan folder untuk keperluan cache, unggah file dsb.

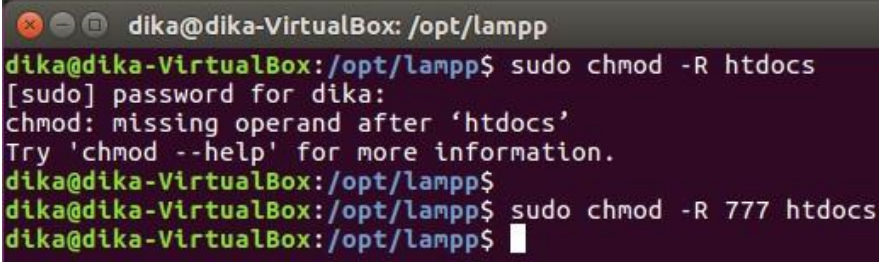

\section{Gambar 13. Pengaturan folder htdocs}

G. Langkah selanjutnya adalah membuat database untuk INLISLite Versi 3.0. Buka browser dan ketikkan localhost/phpmyadmin, kemudian pilih new dan buatlah database dengan nama inlislite_v3.

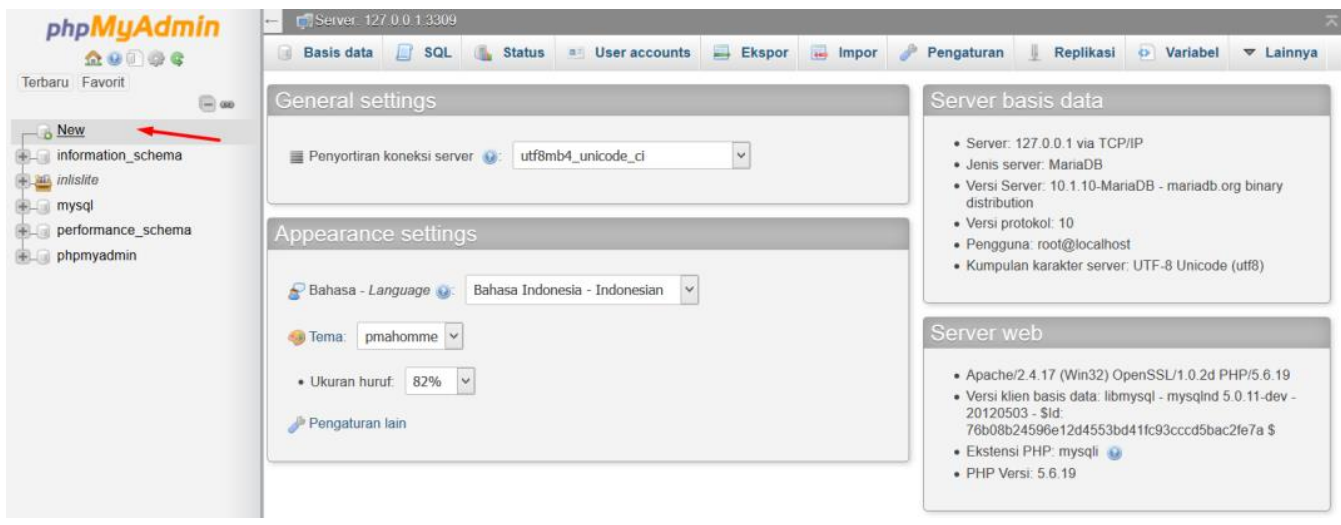

Gambar 14. Halaman awal phpmyadmin

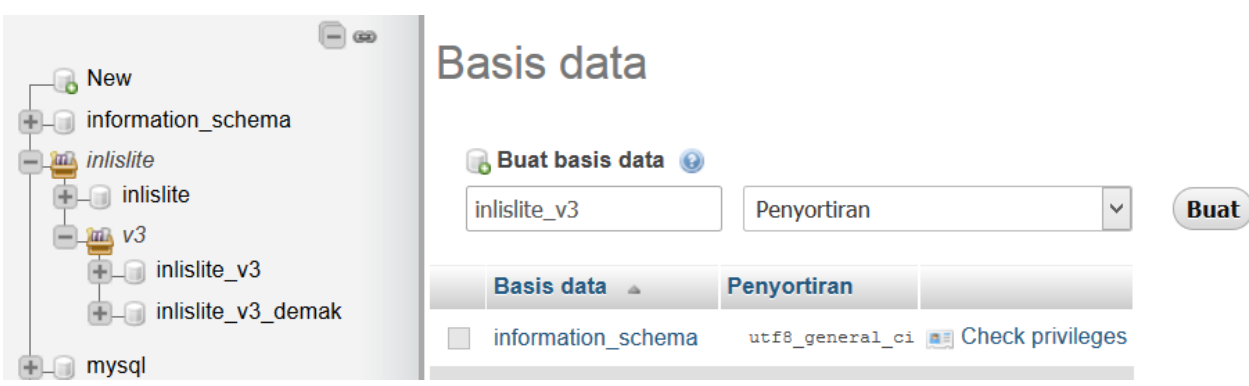

Gambar 15. Buat database baru dengan nama inlislite_v3

H. Lakukan Import dengan klik tab Import dan pilih file database kosong yang sudah diunduh sebelumnya melalui tombol browse dan klik tombol send untuk menjalankan proses import. 


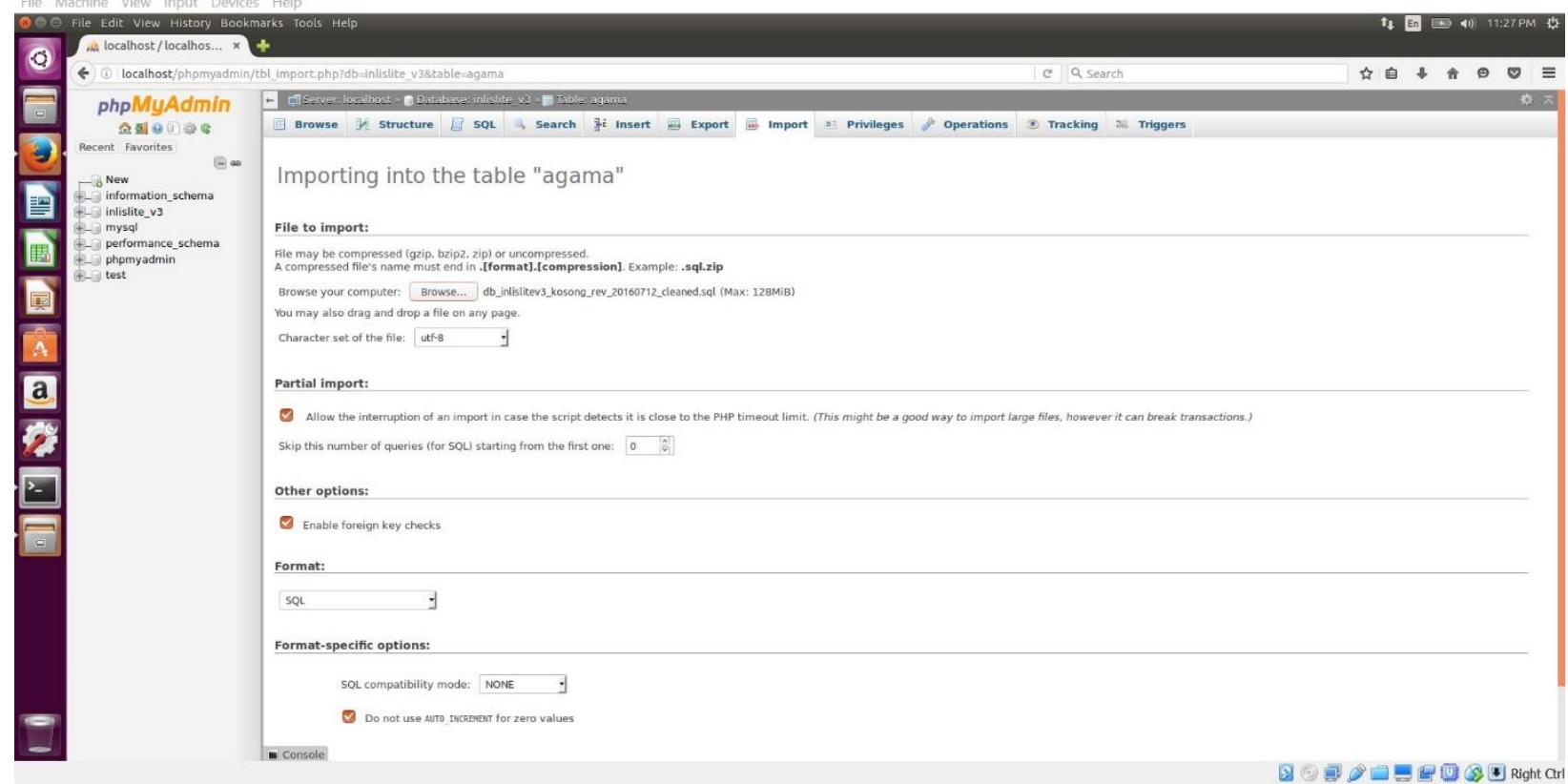

Gambar 16. Import database inlislite_v3

I. Jalankan aplikasi browser Chrome/Mozilla/Opera versi terbaru dan pada kotak alamat URL browser ketikkan http://localhost/inlislite3 lalu tekan tombol enter pada keyboard

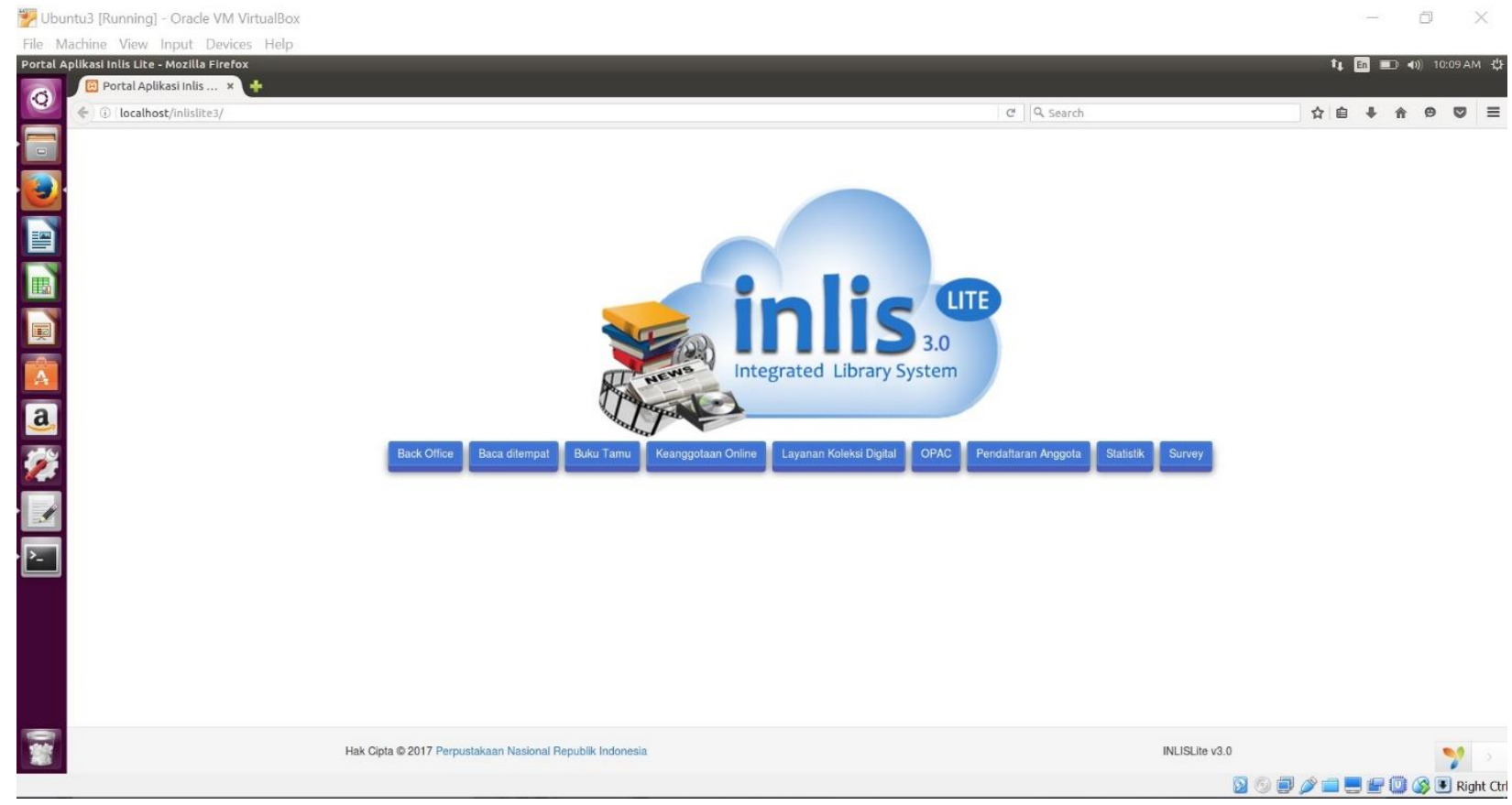

Gambar 17. INLISLite Versi 3 berjalan di browser 